\title{
Malaria reduces globally but rebounds across southern Africa
}

\author{
Lucille Blumberg, John Frean \\ National Institute for Communicable Diseases, National Health Laboratory Service, Johannesburg, South Africa \\ Correspondence to: Lucille Blumberg, e-mail: lucilleb@nicd.ac.za
}

Considerable progress in malaria control has been made in the past five years, with a $21 \%$ decrease in malaria incidence and a $29 \%$ decrease in malaria mortality worldwide. This is due to increased funding, improved use of life-saving interventions and more countries pursuing elimination.

In sub-Saharan Africa, 663 million cases of malaria were prevented between 2001 and 2015 through the scale-up of core malariaprevention tools, which involved the use of either insecticidetreated mosquito nets (ITN) or indoor residual spraying (IRS) of insecticides.

However, by 2015 there were still 212 million cases of malaria and 429000 malaria-related deaths annually, of which 90\% were in sub-Saharan Africa, and mostly affected children under the age of five years. Some $43 \%$ of people at risk of malaria are not protected by ITN or IRS. ${ }^{1}$

Despite these limitations, a new Global Malaria Technical Strategy has set very ambitious goals, milestones and targets for the period 2016-2030, namely: ${ }^{2}$

- reducing malaria mortality rates globally by at least $90 \%$ by 2030

- reducing malaria case incidence globally by at least $90 \%$ by 2030

- eliminating malaria in at least 35 countries by 2030

- preventing a resurgence of malaria in all countries that are malaria free.

Sri Lanka has eliminated malaria and was certified malaria free in October 2016 (elimination is defined as the reduction to zero of the incidence of disease or infection in a defined geographical area). Key components of the country's malaria elimination strategy included targeting both the parasite and the mosquito and upscaling interventions and resources. Driven by a significant political commitment and superbly organised campaign, Sri Lanka has reached the goal of no local malaria transmission. A predominance of Plasmodium vivax made the task more difficult because of its relapsing nature. ${ }^{3}$

Poor rural communities, a predominance of $P$. falciparum, very efficient malaria vectors and limited funding are challenges for similar success in sub-Saharan Africa. Nevertheless, there have been major decreases in malaria prevalence in some countries over the last 15 years, resulting in Namibia, South Africa, Botswana and Swaziland set to eliminate malaria in this decade. A cross-border initiative involving South Africa, Swaziland and
Mozambique, where the transmission risk remains high, has been formally agreed upon. During a previous cross-border programme (2000-2010), malaria incidence was greatly reduced in the border areas of South Africa, with reductions of $90 \%$ in cases (from 64622 to 6846) and 80\% in mortality (from 459 to 91$).^{4-9}$

Mobile populations, competition for resources from coepidemics of HIV and TB, and insecticide resistance remain major challenges.

Malaria made the headlines in 2017, with all southern African countries reporting increased incidence following high ambient temperatures and humidity, and considerable rainfall after a prolonged drought. In South Africa, outbreaks were reported in Limpopo and Mpumalanga provinces. These occurred mostly in traditional malaria transmission areas, but also in areas where IRS, the country's major intervention for malaria control, has been scaled back. Shortages of drugs and rapid tests resulted in public healthcare facilities being overwhelmed during the April holidays. Clearly, a review of the control programme is required to ensure that early warning systems are in place and that adequate supplies for malaria diagnosis and treatment are available.

Swaziland has been consistent in moving towards malaria elimination owing to excellent leadership and a well-resourced elimination programme. Early evidence of resistance to artemisinin has now emerged in Africa and although it is still a limited problem (unlike in southeast Asia), resistance monitoring is essential, especially given the move towards elimination. ${ }^{10,11}$ New vector control tools for targeting residual transmission need to be developed and the role of residual transmission needs to be explored. To achieve elimination, we need to raise our game and implement both sensitive diagnostic tests to detect parasite reservoirs and so break the chain of transmission, and new interventions to target residual transmission. ${ }^{12}$

Additional resources will have to be provided to ensure that hard-won gains in control are not lost and that the elimination agenda progresses.

In the words of Dr Margaret Chan, outgoing director general of the World Health Organization: 'Progress on every front, at every level, is fragile. This is a disease that can take full advantage of any lapse in investment, vigilance or control.'.13 


\section{References}

1. World Health Organization. World Malaria Report 2016. World Health Organization [homepage on the Internet]. 2017. Available from: http://www. who.int/malaria/publications/world-malaria-report-2016/report/en/

2. World Health Organization. Global Technical Strategy for Malaria 2016-2030. World Health Organization [homepage on the Internet]. 2016. Available from: http://www.who.int/malaria/areas/global_technical_strategy/en/

3. Senaratne R, Singh PK. Against the odds, Sri Lanka eliminates malaria. Lancet. 2016 Sep 10; 388(10049):1038-1039. doi: 10.1016/S0140-6736(16)31572-0

4. Raman J, Morris N, Frean J, Brooke B, Blumberg L, Kruger $P$, et al. Reviewing South Africa's malaria elimination strategy (2012-2018): progress, challenges and priorities. Malar J. 2016 Aug 27; 15(1):438. doi: 10.1186/s12936-016-1497-x

5. Moonasar D, Maharaj R, Kunene S, Candrinho B, Saute F, Ntshalintshali N, et al. Towards malaria elimination in the MOSASWA (Mozambique, South Africa and Swaziland) region. Malar J. 2016 Aug 18; 15(1):419. doi: 10.1186/ s12936-016-1470-8

6. Moonasar D, Morris N, Kleinschmidt I, Maharaj R, Raman J, Mayet NT, et al. What will move malaria control to elimination in South Africa? S Afr Med J. 2013 Aug 29; 103(10 Pt 2):801-806. doi: 10.7196/samj.7445

7. Maharaj R, Raman J, Morris N, Moonasar D, Durrheim DN, Seocharan I, et al. Epidemiology of malaria in South Africa: from control to elimination. S Afr Med J. 2013 Aug 29; 103(10 Pt 2):779-783. doi: 10.7196/samj.7441
8. Groepe MA, Urbach J, Jooste H, Hlongwana KW, Baker L, Misiani E, et al. Health promotion: from malaria control to elimination. S Afr Med J. 2013 Aug 29; 103(10 Pt 2):799-800. doi: 10.7196/samj.7444

9. Blumberg L, Frean J, Moonasar D, South African Malaria Elimination Committee. Successfully controlling malaria in South Africa. S Afr Med J. 2014 Mar; 104(3 Suppl 1):224-227.

10. Lu F, Culleton R, Zhang M, Ramaprasad A, Von Seidlein L, Zhou H, et al. Emergence of indigenous artemisinin-resistant Plasmodium falciparum in Africa. N Engl J Med. 2017 Mar 9; 376(10):991-993. doi: 10.1056/NEJMc1612765

11. Sutherland CJ, Lansdell P, Sanders M, Muwanguzi J, Van Schalkwyk DA, Kaur H, et al. Pfk13-independent treatment failure in four imported cases of Plasmodium falciparum malaria treated with artemether-lumefantrine in the United Kingdom. Antimicrob Agents Chemother. 2017 Feb 23; 61(3):e02382-16. doi: 10.1128/AAC.02382-16

12. Burke A, Dandalo L, Munhenga G, Dahan-Moss Y, Mbokazi F, Ngxongo S, et al. A new malaria vector mosquito in South Africa. Sci Rep. 2017 Mar 6; 7:43779. doi: 10.1038/srep43779

13. Chan, M. Progress seen in world malaria report. Statement to the press at the launch of the World Malaria Report 2010. [document on the Internet]. 2010. Available from: http://www.who.int/dg/speeches/2010/ malaria_report_20101214/en/ 